\title{
Cardiac arrhythmias induced by hypokalaemia and potassium loss during maintenance digoxin therapy
}

\author{
E. Steiness and K. H. Olesen \\ From the Department of Medicine B, Rigshospitalet, University of Copenhagen, Denmark
}

Twelve patients with congestive heart failure receiving maintenance therapy with digoxin and potent diuretics were followed closely during development of hypokalaemia and potassium loss. Cardiac arrhythmias compatible with digoxin toxicity developed in 6 patients in the presence of stable, normal serum digoxin concentrations. The mechanisms involved in the development of the rhythm disturbances are discussed with regard to hypokalaemia, intracellular potassium loss, intra-/extracellular potassium gradients and digoxin, and the significance of maintaining a normal potassium balance in this setting is stressed.

It is generally accepted that hypokalaemia and potassium loss may promote digitalis toxicity in patients with congestive heart failure receiving maintenance treatment with digitalis. However, while this situation was frequent in earlier studies of digitalis toxicity (Lown and Levine, 1954; Jorgensen and Sorensen, 1970), hypokalaemia and potassium loss were not observed as causes of digitalis intoxication in more recent reports (Beller et al., 1971; Evered and Chapman, 1971). Though this new trend may reflect better treatment with regard to maintenance of potassium balance during digitalis therapy in particular in patients on chronic diuretic therapy, it seems also possible that the risks involved in hypokalaemia and potassium loss in this setting have been overestimated in the past. In earlier studies of digitalis toxicity in man the relative role of digitalis overdosage and of acute or chronic hypokalaemia or potassium loss have not been precisely defined, and more recent studies in dogs have not supported the concept that hypokalaemia sensitizes the myocardium to digitalis during conditions representing the nearest practical approximation to the situation of patients on chronic diuretic therapy (Kleiger, Vitale, and Lown, 1965; Binnion, 1975).

In an attempt to clarify the significance of hypokalaemia and total potassium deficiency and to evaluate the role of serum digoxin levels in this setting, the present study was planned. Twelve patients with advanced heart failure receiving maintenance therapy with digoxin and potent

Received 16 April 1975. diuretics were subjected to a potassium depleting regimen and followed closely for development of cardiac arrhythmias while serum digoxin concentrations were controlled.

\section{Methods}

Twelve patients with advanced congestive heart failure admitted to Medical Department B, Rigshospitalet Copenhagen, were selected for study according to the following criteria: 1) The subjects had received maintenance digoxin therapy for at least one month and showed normal serum digoxin levels, 2) the patients were in a stable situation on maintenance diuretic treatment, and 3) the subjects presented normal serum potassium concentrations and were apparently in a stable potassium balance while receiving a standard supplement of potassium chloride of $3 \mathrm{~g}$ daily or a potassium sparing drug as additional diuretic if required. The series consisted of 5 men and 7 women; mean age 57.7 years. The clinical diagnoses were rheumatic valvular disease in 6 patients, ischaemic heart disease in 4 , and cardiomyopathy in 2 . The patients received maintenance treatment with digoxin in a dose range from 0.125 to $0.50 \mathrm{mg}$ daily and frusemide 80 to $160 \mathrm{mg}$ or bumetanide 4 to $6 \mathrm{mg}$ per day.

With their informed consent the patients were studied according to the following plan: the electrocardiogram was monitored continuously permitting rapid discontinuation of the study and restoration of potassium balance if required. The maintenance therapy with digoxin and potent diuretics was continued while potassium chloride and potassium sparing drugs were withheld. The patients were studied on a metabolic regimen including a diet restricted in potassium ( $30 \mathrm{mEq}$ daily). Twenty-four hour urinary volumes and excretion of 
potassium were measured. Body weight was determined every morning. At the start of the study total exchangeable potassium $\left(\mathrm{K}_{\mathrm{e}}\right)$ was measured by dilution with $\mathrm{K}^{42}$ (Olesen, 1964). Serum potassium and creatinine were determined every morning (normal range for serum K: 3.5-5.1 mmol/1). Serum digoxin was measured in the fasting state at the start and the end of the study (Steiness, 1974). The study was planned to last 7 days for each patient, but was interrupted immediately if significant arrhythmias occurred.

Serum thyroxine was measured in 10 patients and found to be within the normal range.

\section{Calculation of potassium balance}

The cumulative balance of potassium was determined as summations of daily intakes-renal outputs corrected for faecal and insensible losses (Isaksson, Lindholm, and Sjogren, 1966; Maronde, Milgrom, and Dickey, 1969). The cumulative negative potassium balance was partitioned intoextra- and intracellular losses, and the intra- 1 extracellular potassium gradients were derived as follows.

a) Abbreviations ECW = total extracellular water, $(\mathrm{K}) \mathbf{s}=$ serum potassium concentration, $\mathbf{E C K}=$ total extracellular potassium, ICK $=$ total intracellular potassium, $\mathbf{K}_{\mathbf{e}}=$ total exchangeable potassium (assumed to represent initial body potassium), $\mathrm{K}_{\mathrm{ic}}=$ intracellular potassium concentration, ICW $=$ total intra-cellular water, ' $1 \rightarrow n$ ' indicates the cumulative 24-hour periods of investigation.

b) Starting values $\mathrm{ECW}_{0}=$ body weight $_{0} \times 0.3$, $\mathbf{E C K}_{0}=\mathbf{E C W}_{0} \times(\mathbf{K}) \mathbf{s}_{\mathbf{0}}, \mathbf{I C K}_{\mathbf{0}}=\mathrm{K}_{\mathrm{e}}-\mathbf{E C K}_{\mathbf{0}}$, $\mathrm{ICW}_{0}=\mathrm{ICK}_{0} / 160$, gradient ${ }_{0}=\mathrm{K}_{\mathrm{ic}_{0}} /(\mathrm{K}) \mathrm{s}_{0}$. The basic assumption was made that the average intracellular $\mathrm{K}$ concentration of the body and of the myocardium was $160 \mathrm{mmol} / \mathrm{l}$. at the start of the study (Valentin and Olesen, 1973).

c) Cumulative balance values $\mathrm{ECK}_{1} \rightarrow_{\mathrm{n}}=\left(\mathrm{ECW} \mathrm{W}_{0}\right.$ weight $\left.\operatorname{loss}_{1} \rightarrow_{n}\right) \times(\mathrm{K}) \mathrm{s}_{1} \rightarrow_{\mathrm{n}}, \Delta \mathrm{ECK}_{1} \rightarrow_{\mathrm{n}}=\mathrm{ECK}_{1} \rightarrow_{\mathrm{n}}$, $\mathbf{E C K}_{0}, \quad \mathrm{ICK}_{\mathbf{1}} \rightarrow_{\mathrm{n}}=\mathrm{ICK}_{0}+\left(\Delta \mathrm{K}\right.$ balance $_{\mathbf{1}} \rightarrow_{\mathrm{n}}-$
$\left.\Delta \mathrm{ECK}_{1} \rightarrow_{\mathrm{n}}\right), \Delta \mathrm{ICK}_{1} \rightarrow_{\mathrm{n}}=\mathrm{ICK}_{1} \rightarrow_{\mathrm{n}}-\mathrm{ICK}_{0}, \mathrm{~K}_{\mathrm{ic1}} \rightarrow_{\mathrm{n}}$ $=\mathrm{ICK}_{1} \rightarrow_{\mathrm{n}} / \mathrm{ICW}_{0}$.

Intra-/extracellular potassium gradients were calculated according to two models. Model I: gradient $\mathrm{I}_{1} \rightarrow_{\mathrm{n}}=\mathrm{K}_{\mathrm{ic1}} \rightarrow_{\mathrm{n}} /(\mathrm{K}) \mathrm{s}_{1} \rightarrow_{\mathrm{n}}, \Delta$ gradient $\mathrm{I}_{1} \rightarrow_{\mathrm{n}}=$ gradient $\mathrm{I}_{1} \rightarrow_{\mathrm{n}}$ - gradient $\mathrm{I}_{0}$. Model II : gradient II was calculated as shown above under the assumption that the myocardial intracellular potassium concentration remained unchanged during the study (Bolte, 1973).

\section{Interpretation of electrocardiogram}

The continuous monitoring of the electrocardiogram and tracings of one minute's duration taken at least twice daily were analysed for arrinythmias, usually ascribed to digoxin toxicity (Evered and Chapman, 1971).

\section{Results}

Cardiac arrhythmias occurred in 6 out of 12 patients $(50 \%)$ within the week of the study. Four patients developed ventricular premature beats either as multifocal ectopic beats or as bigeminy. Two patients showed atrial premature beats with prolonged PQ intervals. All 6 patients showed hypokalaemia and overall potassium loss when the arrhythmias occurred. In 2 patients interruption of the study became necessary after 3 and 4 days because of the development of rhythm disturbances. In the remaining 4 patients the arrhythmias only occurred on the last day of the study.

Serum digoxin concentrations showed a mean value of $1.52 \pm 0.17 \mathrm{nmol} / \mathrm{ml}(1.19 \pm 0.13 \mathrm{ng} / \mathrm{ml})$ at the start of the study and did not change significantly during the experiment. The daily oral dose of digoxin was $0.30 \pm 0.06 \mathrm{mg}$. As shown in Table 1 the mean values and the trends were exactly the same in the group developing arrhythmias and in the group without. Similarly, serum creatinine concentrations were the same in the two groups and remained unchanged during the study.

TABLE 1 Summary of data in patients on maintenance digoxin therapy (mean values $\pm S E M$ )

\begin{tabular}{|c|c|c|c|c|c|c|c|}
\hline & \multirow[t]{2}{*}{ No. } & \multirow[t]{2}{*}{ Age (yr) } & \multirow{2}{*}{$\begin{array}{l}\text { Average } \\
\text { daily } \\
\text { digoxin } \\
\text { dose (mg) }\end{array}$} & \multicolumn{2}{|c|}{$\begin{array}{l}\text { Serum digoxin } \\
\text { concentration } \\
(\text { nmol } / \text { ml })\end{array}$} & \multicolumn{2}{|c|}{$\begin{array}{l}\text { Serum creatinine } \\
\text { concentration } \\
(\text { mmol/l) }\end{array}$} \\
\hline & & & & Before & After & Before & After \\
\hline $\begin{array}{l}\text { All subjects } \\
\text { Subjects developing } \\
\text { arrhythmias } \\
\text { Subjects not developing } \\
\text { arrhythmias }\end{array}$ & $\begin{array}{l}12 \\
M: 5, F: 7 \\
6 \\
M: 2, F: 4 \\
6 \\
M: 3, F: 3\end{array}$ & $\begin{array}{r}57.7 \\
+3.7 \\
59.5 \\
+3.9 \\
55.8 \\
+6.6\end{array}$ & $\begin{array}{c}0.30 \\
\pm 0.06 \\
0.28 \\
+0.04 \\
0.32 \\
\pm 0.05\end{array}$ & $\begin{array}{c}1.52 \\
+0.17 \\
1.51 \\
+0.29 \\
1.54 \\
\pm 0.18\end{array}$ & $\begin{array}{l}1.69 \\
\pm 0.23 \\
1.63 \\
+0.37 \\
1.77 \\
\pm 0.23\end{array}$ & $\begin{array}{c}0.11 \\
+0.01 \\
0.11 \\
+0.01 \\
0.11 \\
\pm 0.02\end{array}$ & $\begin{array}{l}0.11 \\
\pm 0.01 \\
0.11 \\
+0.01 \\
0.11 \\
\pm 0.01\end{array}$ \\
\hline
\end{tabular}

Conversion from SI to traditional units: digoxin $1 \mathrm{nmol} \approx 0.78 \mathrm{ng}$. 
TABLE 2 Summary of data on potassium balance (absolute values given as mean values $\pm S E M$ )

\begin{tabular}{|c|c|c|c|c|c|c|c|}
\hline & No. & $\begin{array}{l}\text { Serum } \\
\text { potassium } \\
\text { (mmol } / l) \\
\text { Before }\end{array}$ & After & $\begin{array}{l}\text { Total } \\
\text { exchangeable } \\
\text { potassium } \\
\text { (mmol) }\end{array}$ & $\begin{array}{l}\text { Total } \\
\text { K balance } \\
\text { (mmol) }\end{array}$ & $\begin{array}{l}\text { Total } \\
\text { extracellular } \\
\boldsymbol{K} \text { balance } \\
\text { (mmol) }\end{array}$ & $\begin{array}{l}\text { Total } \\
\text { intracellular } \\
\boldsymbol{K} \text { balance } \\
\text { (mmol) }\end{array}$ \\
\hline All subjects & 12 & $\begin{array}{r}4.37 \\
+0.10\end{array}$ & $\begin{array}{r}3.41 \\
+0.00\end{array}$ & 1890 & -204 & $\begin{array}{l}-21 \\
+?\end{array}$ & -183 \\
\hline $\begin{array}{l}\text { Subjects developing } \\
\text { arrhythmias } \\
\text { Subjects not developing } \\
\text { arrhythmias }\end{array}$ & $\begin{array}{l}6 \\
6\end{array}$ & $\begin{array}{r}+4.45 \\
+0.13 \\
4.28 \\
+0.17\end{array}$ & $\begin{array}{r}3.45 \\
+0.15 \\
+3.37 \\
+0.13\end{array}$ & $\begin{array}{l}1918 \\
+241 \\
1861 \\
\pm 106\end{array}$ & $\begin{array}{l} \pm 204 \\
\pm 26 \\
-204 \\
\pm 32\end{array}$ & $\begin{array}{l} \pm 24 \\
\pm 3 \\
-18 \\
\pm 4\end{array}$ & $\begin{array}{l}-180 \\
\pm 27 \\
-184 \\
\pm 31\end{array}$ \\
\hline
\end{tabular}

\section{Potassium metabolism}

As shown in Table 2 the regimen used proved effective in reducing serum potassium concentration from a mean value of $4.37 \mathrm{mmol} / 1$ at the start to a mean of $3.41 \mathrm{mmol} / 1$ at the end of the study. The development of hypokalaemia was associated with a mean total potassium loss of $204 \mathrm{mmol} .21 \mathrm{mmol}$ (or $10 \%$ of total potassium loss) originated from the extracellular phase while the remaining $183 \mathrm{mmol}$ (or $90 \%$ of total potassium loss) was lost from the intracellular phase. The cumulative changes in potassium balance for 10 patients studied for a full week is shown in Fig. 1. Apparently, the decrease of serum potassium concentration and of total body potassium was most pronounced during the first 4 to 5 days of the study.

The degree of hypokalaemia and of total potassium loss obtained was very similar in the group developing arrhythmias to that in the group without (Table 2).

For the whole group the total potassium loss amounted to 11 per cent of initial body potassium (Table 3). Of particular significance is the fact that the total extracellular loss represents 26 per cent of the initial total extracellular potassium whereas the total intracellular loss amounts to only 11 per cent of the initial total intracellular potassium. The relatively larger loss from the extracellular phase results in a rise in the intra-/extracellular potassium gradient 1 (model I) for the whole body (Table 3 and Fig. 2). An even larger rise is seen in the myo-
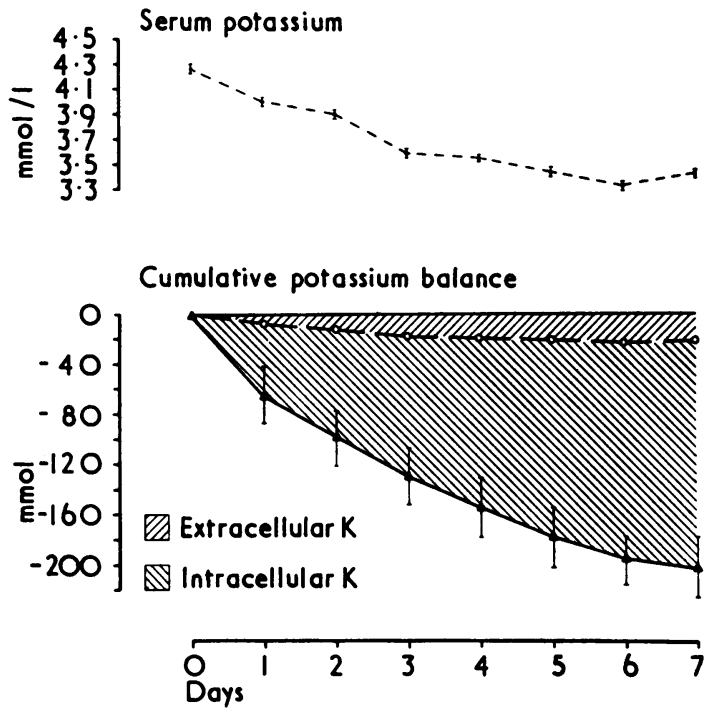

FIG. I Serum potassium concentration and cumulative $K$ balance in 10 patients receiving a $K$ depleting regimen for 7 days. Mean values ( $\pm S E M$ ) are given.

TABLE 3 Summary of data on potassium balance (relative values given as mean values $\pm S E M$ )

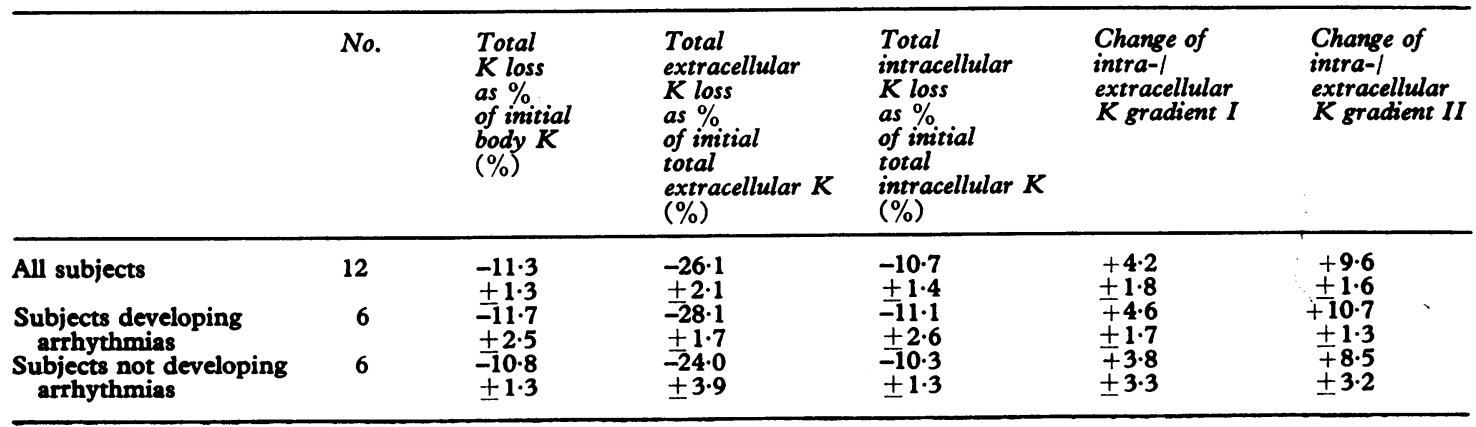




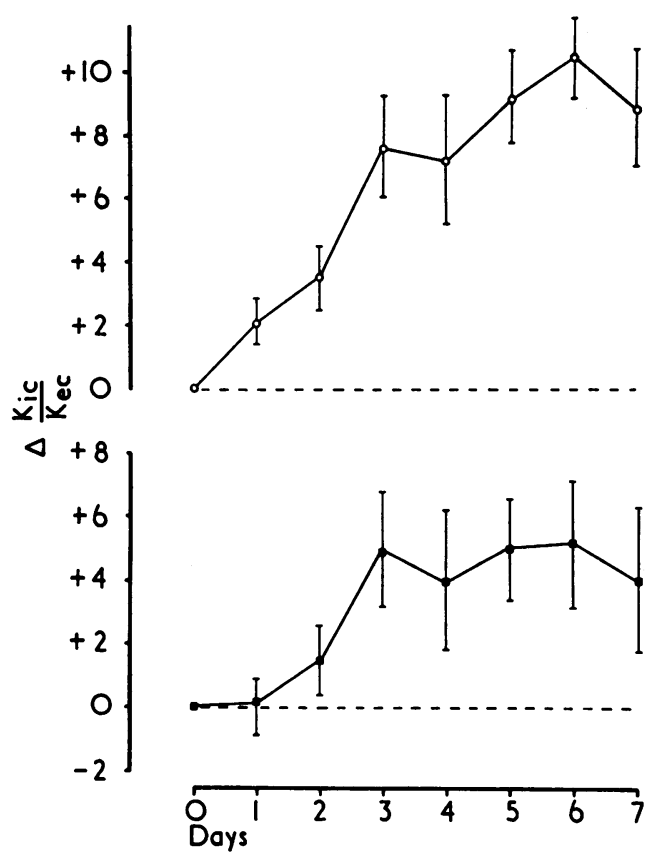

FIG. 2 Changes in intra-/extracellular $K$ gradients in 10 patients receiving a $K$ depleting regimen for 7 days. Mean values ( $\pm S E M)$ are given. The upper panel shows the myocardial $K$ gradient (calculated on the assumption of an unchanged intracellular $K$ concentration); the lower panel shows the $K$ gradient for the whole body.

cardial intra-/extracellular potassium gradient II (model II) which is derived on the assumption that myocardial intracellular potassium concentration remains unchanged while distinct hypokalaemia develops (Table 3 and Fig. 2).

The partitioning of the potassium loss and the changes in intra-/extracellular potassium gradients were the same in the group developing arrhythmias and in the group without (Table 3 ).

\section{Discussion}

The study was performed in patients with advanced congestive heart failure receiving maintenance digoxin therapy. The mean serum digoxin concentration was $1.52 \pm 0.17 \mathrm{nmol} / 1(1.19 \pm 0.13$ $\mathrm{ng} / \mathrm{ml}$ ) at the start of the study and did not change significantly during the experiment. The average daily dose of digoxin was $0.30 \pm 0.06 \mathrm{mg}$. In terms of serum digoxin values and daily digoxin doses our findings are in good agreement with other recent studies (Beller et al., 1971 ; Carruthers, Kelly, and McDevitt, 1974).
In this setting 6 out of 12 patients developed cardiac arrhythmias fulfilling the criteria of digitalis toxicity. The arrhythmias occurred at serum digoxin levels which are usually not associated with toxic manifestations and were apparently precipitated by the development of chronic hypokalaemia and potassium loss.

There is evidence that acute hypokalaemia in patients given digitalis may provoke such arrhythmias as well after carbohydrate administration which displaces potassium from the extracellular to the intracellular phase as after potassium loss during haemodialysis (Page, 1955; Lubash et al., 1959; Kunin, Surawicz, and Sims, 1962). The mechanisms of interplay between digitalis, hypokalaemia, and potassium loss are not clear, however. While in earlier dog experiments, acetyl strophanthidin produced rhythm disturbances at a lower dose after acute hypokalaemia induced by glucose and insulin infusion or haemodialysis than in normal dogs (Lown et al., 1952; Kleiger et al., 1965), this pattern was not reproduced in a recent study in acutely hypokalaemic dogs where digoxin was infused until atrioventricular dissociation occurred (Binnion, 1975). There is evidence that acute reduction of extracellular potassium concentration increases the ability of the myocardium to take up circulating digoxin (Cohn, Kleiger, and Harrison, 1967; Prindle et al., 1969). However, the myocardial concentration of digoxin appears to be the same in normal and in acutely hypokalaemic dogs at the time of digitalis induced ventricular tachycardia or atrioventricular dissociation (Binnion and Das Gupta, 1974; Binnion, 1975).

Although chronic hypokalaemia and potassium loss induced by diuretics as found in the present study are generally accepted as being able to sensitize the myocardium to the arrhythmogenic effects of digitalis in man, the available evidence for this assumption is scanty (Callahan et al., 1952; Lown et al., 1952; Jorgensen and Sorensen, 1970; Salvador et al., 1970; Binnion, 1975; PooleWilson, Hall, and Cameron, 1975). Moreover, an animal experimental model, similar to the patient on chronic digitalis and diuretic therapy, has never been produced. In dogs with chronic hypokalaemia and potassium deficiency induced by dietary restriction of potassium and/or diuretics, an increased sensitivity of the myocardium to acute loads of acetyl strophanthidin or of digoxin could not be demonstrated (Kleiger et al., 1965; Binnion, 1975). It may be concluded, however, that our findings are in keeping with the view that chronic hypokalaemia and potassium loss may sensitize the myocardium to digitalis in man. 
In terms of electrophysiological mechanisms the appearance of cardiac arrhythmias in this setting can be explained by an increased automaticity of lower pacemakers and by a decreased atrioventricular conduction induced by digoxin in a sensitized myocardium (Surawicz and Gettes, 1971). However, the alternative possibility that the arrhythmias are induced by hypokalaemia alone must also be considered.

In the present series the degree of potassium depletion induced is reflected by the slow and gradual decrease of serum potassium of $1 \mathrm{mmol} / 1$ and by an overall potassium loss of $204 \mathrm{mmol}$ or 11 per cent of body potassium. As shown in Tables 2 and 3 the relative loss of potassium was larger from the extracellular than from the intracellular phase, resulting in a rise in the intra-/extracellular potassium gradient for the whole body. Our findings stress the significance of hypokalaemia as a factor in the alterations in the intra-/extracellular potassium gradient, as pointed out by other authors (Surawicz and Gettes, 1971). An even larger increase is found when the myocardial intra- $/$ extracellular potassium gradient is calculated on the assumption that the intracellular concentration of the myocardium remains unchanged during the study (Bolte, 1973; St. George et al., 1955; Hall and Cameron, 1974). The electrophysiological effects of a rise in the intra-/extracellular gradient are an increased automaticity of ectopic pacemaker activity and a decreased atrioventricular conduction similar to the actions of digitalis.

In clinical experience atrial and ventricular premature beats or rhythms induced by hypokalaemia are described in patients, not on digitalis, with an incidence ranging from 20 to 40 per cent. Higher frequencies are found in patients with organic heart disease and in those given digitalis (Surawicz et al., 1957; Weaver and Burchell, 1960; Davidson and Surawicz, 1967). In our series arrhythmias were observed in 50 per cent during one week of study, and a higher incidence might have been expected with a longer period of study. A comparison between the incidence in our series and in earlier reports is difficult because of the differences in the settings studied and in methods used. Consequently, the question remains undecided whether the arrhythmias are caused by hypokalaemia or are caused by a combined effect of changes in potassium balance and of digoxin.

From a clinical point of view, however, the important fact is that hypokalaemia can precipitate cardiac arrhythmias in patients receiving maintenance digoxin therapy. It is necessary, therefore, to ensure the maintenance of normal potassium balance during long-term digitalis therapy.

\section{References}

Beller, G. A., Smith, T. W., Abelmann, W. H., Haber, E., and Hood, W. B., Jr. (1971). Digitalis intoxication. A prospective clinical study with serum level correlations. New England fournal of Medicine, 284, 989.

Binnion, P. F. (1975). Hypokalaemia and digoxin-induced arrythmias. Lancet, 1, 343.

Binnion, P. F., and Das Gupta, R. (1974). Digitalis-induced ventricular tachycardia. A study of tissue levels. Circulation 50, Suppl. III, 215.

Bolte, H.-D. (1973). Treatment of acute and chronic hypokalemia. Acta Cardiologica, Suppl. 17, 211.

Callahan, E. J., Frank, N. R., Kraus, H., and Ellis, L. B. (1952). Clinical use of cation exchange resins in the treatment of congestive heart failure. American fournal of the Medical Sciences, 223, 117.

Carruthers, S. G., Kelly, J. G., and McDevitt, D. G. (1974). Plasma digoxin concentrations in patients on admission to hospital. British Heart fournal, 36, 707.

Cohn, K. E., Kleiger, R. E., and Harrison, D. C. (1967). Influence of potassium depletion on myocardial concentration of tritiated digoxin. Circulation Research, 20, 473.

Davidson, S., and Surawicz, B. (1967). Ectopic beats and atrioventricular conduction disturbances. In patients with hypopotassemia. Archives of Internal Medicine, 120, 280.

Evered, D. C., and Chapman, C. (1971). Plasma digoxin concentrations and digoxin toxicity in hospital patients. British Heart fournal, 33, 540.

Hall, R. J. C., and Cameron, I. R. (1974). The intracellular $\mathrm{pH}$ and potassium content of rabbit cardiac and skeletal muscle in potassium depletion. Clinical Science and Molecular Medicine, 47, $24 \mathrm{P}$.

Isaksson, B., Lindholm, B., and Sjogren, B. (1966). Dermal losses of nutrients and their significance for human metabolic balance studies. Acta Medica Scandinavica, Suppl. $445,416$.

Jorgensen, A. W., and Sorensen, O. H. (1970). Digitalis intoxication. A comparative study of the incidence of digitalis intoxication during the periods 1950-52 and 1964-66. Acta Medica Scandinavica, 188, 179.

Kleiger, R. E., Vitale, J., and Lown, B. (1965). Clinical and experimental relationships between digitalis and potassium. Proceedings of the New England Cardiovascular Society, 23, 19.

Kunin, A. S., Surawicz, B., and Sims, E. A. H. (1962). Decrease of serum potassium concentrations and appearance of cardiac arrhythmias during infusion of potassium with glucose in potassium-depleted patients. New England Fournal of Medicine, 266, 228.

Lown, B., and Levine, S. A. (1954). Current concepts in digitalis therapy. New England fournal of Medicine, 250, 771, 819, 866.

Lown, B., Weller, J. M., Wyatt, N., Hoigne, R., and Merrill, J. P. (1952). Effects of alterations of body potassium on digitalis toxicity. Fournal of Clinical Investigation, 31, 648.

Lubash, G. D., Cohen, B. D., Braveman, W. S., Robin, A. L., and Luckey, E. H. (1959). Electrocardiographic changes during hemodialysis with the artificial kidney. Circulation, 19, 552.

Maronde, R. F., Milgrom, M., and Dickey, J. M. (1969). Potassium loss with thiazide therapy. American Heart fournal, 78, 16.

Olesen, K. H. (1964). Body composition in heart disease: total exchangeable potassium, total exchangeable sodium, total exchangeable chloride and derived values for body composition in cardiac disease with and without edema. Acta Medica Scandinavica, 175, 301. 
Page, E. (1955). Precipitation of ventricular arrhythmias due to digitalis by carbohydrate administration. American Fournal of Medicine, 19, 169.

Poole-Wilson, P. A., Hall, R., and Cameron, I. R. (1975). Hypokalaemia, digitalis and arrhythmias. Lancet, 1, 575.

Prindle, K. H., Skelton, C. L., Epstein, S. E., and Marcus, F. I. (1969). Influence of extracellular potassium concentration on myocardial uptake and inotropic effect of tritiated digoxin. Circulation, 39-40, Suppl. III, 165.

Salvador, M., Thomas, C., Mazenq, M., Conté, J., Mériel, P., and Lesbre, P. (1970). Troubles du rythme directement induits ou favorisés par les déplétions potassiques. Archives des Maladies du Coeur et des Vaisseaux, 63, 230.

St. George, S., Freed, S. C., Roseman, R. H., and Winderman, S. (1955). Influence of potassium deprivation and adrenalectomy on potassium concentration of the myocardium. American fournal of Physiology, 181, 550.

Steiness, E. (1974). Renal tubular secretion of digoxin. Circulation, 50, 103.

Surawicz, B., Braun, H. A., Crum, W. B., Kemp, R. L.,
Wagner, S., and Bellet, S. (1957). Quantitative analysis of the electrocardiographic pattern of hypopotassemia. Circulation, 16, 750.

Surawicz, B., and Gettes, L. S. (1971). Effects of electrolyte abnormalities on the heart and circulation. In Cardiac and Vascular Diseases, p. 539. Ed. by H. L. Conn, Jr., and $\mathrm{O}$. Horwitz. Lea and Febiger, Philadelphia.

Valentin, N., and Olesen, K. H. (1973). Muscle electrolytes and total exchangeable electrolytes in patients with cardiac diseases. Scandinavian fournal of Clinical and Laboratory Investigation, 32, 161.

Weaver, W. F., and Burchell, H. B. (1960). Serum potassium and the electrocardiogram in hypokalemia. Circulation, 21, 505.

Requests for reprints to Dr. K. H. Olesen, Department of Medicine B, Rigshospitalet, Blegdamsvej 9, 2100 Copenhagen O. Denmark. 